\title{
Renal Association Clinical Practice Guideline on Cardiovascular Disease in CKD
}

\author{
Dr Stephen Holt ${ }^{a}$ and Dr David Goldsmith ${ }^{b}$ \\ ${ }^{a}$ Consultant Nephrologist, Sussex Kidney Unit, Brighton \\ ${ }^{b}$ Consultant Nephrologist, Guys and St. Thomas' NHS Foundation Trust
}

\section{Key Words}

cardiovascular disease $\cdot$ chronic kidney disease $\cdot$ hypertension - risk factors $\cdot$ secondary prevention $\cdot$ revascularisation

\section{Introduction}

This clinical practice guideline provides recommendations on the prevention and management of cardiovascular disease in patients with chronic kidney disease (CKD) and serves as an update of the 4th edition module published online in 2007 (www.renal.org). The literature in the English language has been searched and reviewed to take account of studies that have been published between 2006 and February 2010 using a strategy based on the search terms listed below:

Mortality AND (dialysis OR renal failure)

Smoking AND (dialysis OR renal failure)

Diabetic control AND (dialysis OR renal failure)

Cholesterol AND (dialysis OR renal failure)

Lipids AND (dialysis OR renal failure)

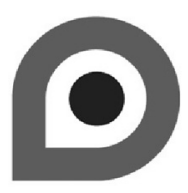

NHS Evidence Accreditation Mark
Homocysteine AND (dialysis OR renal failure)

(Folic acid OR folate) AND (dialysis OR renal failure)

Cardiovascular disease AND (dialysis OR renal failure)

Coronary artery disease AND (dialysis OR renal failure)

Ischaemic heart disease AND (dialysis OR renal failure)

Cardiovascular risk AND (dialysis OR renal failure)

Exercise AND (dialysis OR renal failure)

(Blood pressure OR hypertension) AND (dialysis OR renal failure)

(Blood pressure OR hypertension) AND (dialysis OR renal failure)

The recommendations in this update have been graded using the modified GRADE system $[1,2]$ to indicate both the strength of each recommendation (strong or weak) and level of evidence for the recommendation (A-D). Thus, the grading of the recommendations ranges from $1 \mathrm{~A}-2 \mathrm{D}$.

The recommendations within this guideline have been harmonised with other national guidance on the

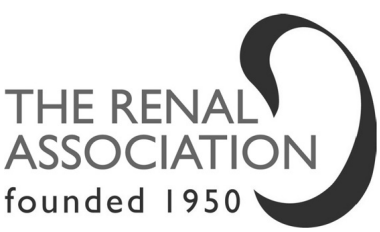

Dr Stephen Holt and Dr David Goldsmith

Email: steve.holt@bsuh.nhs.uk or david.goldsmith@gstt.nhs.uk

\section{KARGER}

Fax +4161306 1234

E-Mail karger@karger.ch

www.karger.com
C) 2011 S. Karger AG, Base

1160-2110/11/1185-000125\$38.00/0 
management of cardiovascular disease in CKD whenever possible and this guideline supports the recommendations on cardiovascular management of the Joint British Societies [3] and National Collaborating Centre for Chronic Conditions [4].

Guidance on blood pressure measurement and targets in the subgroup of CKD patients on haemodialysis was not included in the last edition given the difficulty in providing recommendations on this topic based on evidence. The recent KDIGO controversies conference on hypertension in dialysis patients re-affirmed this viewpoint [5] and so it is not planned to include recommendations on treatment of hypertension in dialysis patients in the KDIGO guideline on hypertension in
CKD due in 2011 [6]. However, as clinical staff have requested guidance on the treatment of hypertension in dialysis patients, pre- and post-dialysis blood pressure levels are audited by the UK Renal Registry and a recent meta-analysis broadly supports the lowering of high levels of blood pressure in dialysis patients [7], we have included a section on the management of hypertension in dialysis patients in this edition using the modified GRADE system to qualify its recommendations appropriately with the level of evidence available. The reader is referred to the KDIGO website which is a useful site of reference for comparison of evidence based guidelines internationally [6].

\section{References}

1 Guyatt GH, Oxman AD, Vist GE, Kunz R, Falck-Ytter Y, Alonso-Coello P, et al. GRADE: an emerging consensus on rating quality of evidence and strength of recommendations. BMJ 2008;336(7650):924-926

2 Uhlig K, Macleod A, Craig J, Lau J, Levey AS, Levin A, et al. Grading evidence and recommendations for clinical practice guidelines in nephrology. A position statement from Kidney Disease: Improving Global Outcomes (KDIGO). Kidney Int 2006;70(12):2058-2065

- 3 British Hypertension Society British Cardiac Society. JBS 2: Joint British Societies' guidelines on prevention of cardiovascular disease in clinical practice. Heart 2005;91(Suppl 5):v1-52

4 National Collaborating Centre for Chronic Conditions. Chronic kidney disease: national clinical guideline for early identification and management in adults in primary and secondary care. 2008
5 Levin NW, Kotanko P, Eckardt K, Kasiske BL, Chazot C, Cheung AK, et al. Blood pressure in chronic kidney disease stage 5D-report from a Kidney Disease: Improving Global Outcomes controversies conference. Kidney Int [Internet] 2009 [cited 2009 Dec 19]; Available from: http://www.ncbi. nlm.nih.gov/pubmed/20016467

6 www.kdigo.org

7 Heerspink HJL, Ninomiya T, Zoungas S, de Zeeuw D, Grobbee DE, Jardine $\mathrm{MJ}$, et al. Effect of lowering blood pressure on cardiovascular events and mortality in patients on dialysis: a systematic review and meta-analysis of randomised controlled trials. Lancet 2009;373(9668):1009-1015 


\section{Summary of Clinical Practice Guidelines for Cardiovascular Disease in CKD}

\section{Cardiovascular disease in CKD (CVD) (Guidelines CVD 1.1-1.8)}

\section{Guideline 1.1 - CVD: Cardiovascular risk factors}

We recommend that a history of and risk factors for cardiovascular disease in patients with CKD Stage 1-5 and dialysis patients should be recorded in a format that permits audit of the management of such patients (1B).

These should include:

- Angina and myocardial infarction

- Previous coronary angioplasty or coronary artery bypass grafting

- Stroke and transient ischaemic attack

- Previous carotid artery surgery or angioplasty

- Peripheral vascular disease or previous intervention

- Cardiac failure

- Arrhythmias (supraventricular and ventricular)

- Diabetes

- Ethnicity

\section{Guideline 1.2 - CVD: Cardiovascular risk factors}

We recommend that a healthy lifestyle should be encouraged in all CKD patients, including dialysis patients. (1C)

\section{Guideline 1.3 - CVD: Cardiovascular risk factors}

We suggest that smoking habits should be recorded and smoking should be actively discouraged in all patients with a reasonable life expectancy and strongly discouraged in those patients on the transplant waiting list. (2B)

\section{Guideline 1.4 - CVD: Cardiovascular risk factors}

We suggest that exercise should be encouraged and patients, including dialysis patients, should be enrolled on regular exercise programmes, exercising 3 to 5 times weekly either during dialysis or between dialysis sessions. (2C)

\section{Guideline 1.5 - CVD: Cardiovascular risk factors}

We suggest that the target glycated haemoglobin $\left(\mathrm{HbA} 1_{\mathrm{c}}\right)$ in all $\mathrm{CKD}$, dialysis and transplant patients with diabetes should be between $6.5 \% \quad(48 \mathrm{mmol} /$ $\left.\mathrm{mmol} / \mathrm{HbA}_{0}\right)$ and $7.5 \%\left(58 \mathrm{mmol} / \mathrm{mmol} / \mathrm{HbA}_{0}\right)$. (2C)
Guideline 1.6 - CVD: Cardiovascular risk factors

We recommend that statins (or 3 hydroxy-3methylglutaryl-coenzyme A reductase inhibitors) should be considered for primary prevention in all CKD Stages 1-4 and transplant patients with a 10-year risk of cardiovascular disease, calculated as $>20 \%$ according to the Joint British Societies' Guidelines - JBS2-(British Hypertension Society British Cardiac Society 2005). (1B)

\section{Guideline 1.7 - CVD: Cardiovascular risk factors}

We recommend that a total cholesterol of $<4 \mathrm{mmol} / \mathrm{l}$ or a $25 \%$ reduction from baseline, or a fasting low density lipoprotein (LDL)-cholesterol of $<2 \mathrm{mmol} / \mathrm{l}$ or a $30 \%$ reduction from baseline, should be achieved, whichever is the greatest reduction in all patients. (1B)

\section{Guideline 1.8 - CVD: Cardiovascular risk factors}

We suggest that statins should not be withdrawn from patients in whom they were previously indicated and should continue to be prescribed when such patients start renal replacement therapy (RRT) or change modality. (2C)

\section{Cardiovascular disease in CKD (CVD) (Guidelines CVD 2.1-2.3)}

\section{Guideline 2.1 - CVD: B vitamin and folate supplementation}

We suggest that folic acid and B vitamin supplements should be offered to all renal patients considered nutritionally at risk from deficiency of folic acid or B vitamin deficiency. B12 levels and, serum and red cell folate should be above the lower limit of the reference range in all CKD patients including patients on dialysis and after transplantation. (2C)

\section{Guideline 2.2 - CVD: Folate deficiency}

We suggest that red cell folate levels should be checked if $\mathrm{MCV}$ remains high despite normal or high serum folate. $(2 \mathrm{C})$

\section{Guideline 2.3-CVD: Hyperhomocysteinaemia and} vitamin supplementation

We suggest that serum folate levels and B12 should be checked 6 monthly in CKD4/5 and 3 monthly in dialysis patients or more frequently if patients remain anaemic or deficient on initial sampling. There is insufficient evidence of the effects of these vitamins on modifying vascular risk by effects on homocysteine in dialysis patients to recommend supraphysiological replacement. (2D) 


\section{Cardiovascular disease in CKD (CVD) (Guidelines CVD 3.1-3.6)}

\section{Guideline 3.1 - CVD: Secondary prevention of cardiovascular risk}

We recommend that CKD Stage 1-3 patients with a history of chronic stable angina, acute coronary syndrome, myocardial infarction, stroke, peripheral vascular disease, or who undergo surgical or angiographic coronary revascularisation, should be prescribed aspirin, an ACE inhibitor, a beta-blocker, and an HMG-CoA reductase inhibitor unless contraindicated as per NICE Guidance. (1B)

\section{Guideline 3.2 - CVD: Secondary prevention of cardiovascular risk}

We suggest that CKD Stage 4/5 patients (including those on dialysis and after transplantation) with a history of chronic stable angina, acute coronary syndrome, myocardial infarction, stroke, peripheral vascular disease, or who undergo surgical or angiographic coronary revascularisation, should be prescribed aspirin, an ACE inhibitor, a beta-blocker, and an HMG-CoA reductase inhibitor unless contraindicated as per NICE Guidance. $(2 \mathrm{C})$

\section{Guideline 3.3 - CVD: Secondary prevention of cardiovascular risk}

We suggest that aspirin and clopidogrel may be indicated for up to 12 months post angioplasty and stenting and in non-ST elevation MI but may have an excess of bleeding complications. (2C)

\section{Guideline 3.4 - CVD: Secondary prevention of cardiovascular risk}

We suggest that aspirin is indicated for secondary prevention but not primary prevention of vascular disease in renal failure. $(2 \mathrm{C})$

\section{Guideline 3.5 - CVD: Secondary prevention of cardiovascular risk}

We suggest that the doses of ACE inhibitors and betablockers should be titrated upwards to the maximal effective or tolerated dose. (2C)

\section{Guideline 3.6 - CVD: Secondary prevention of cardiovascular risk}

We suggest that patients on lipid-lowering drug treatment should have total cholesterol reduced by $25 \%$ or to below $4 \mathrm{mmol} / \mathrm{l}$, or LDL-cholesterol to below
$2 \mathrm{mmol} / \mathrm{l}$, or reduced by $30 \%$, whichever reductions are the greatest. (2B)

\section{Cardiovascular disease in CKD (CVD) (Guidelines CVD 4.1-4.3)}

\section{Guideline 4.1 - CVD: Cardiac investigations and coronary revascularisation}

We suggest that CKD and dialysis patients should have unimpeded access to a full range of cardiac investigations including exercise and stress echocardiography, radioisotopic cardiac scans, and coronary angiography. They should also have unimpeded access to cardiology assessment for coronary angioplasty, coronary stenting and cardiac surgery. (2D)

\section{Guideline 4.2 - CVD: Cardiac investigations and coronary revascularisation}

We suggest that there should be no clinically important delay for pre-dialysis and dialysis patients in receiving assessment by cardiology colleagues for their suitability for transplantation. These issues are often best addressed by regular/joint working with other disciplines. (2D)

\section{Guideline 4.3 - CVD: Cardiac investigations and coronary revascularisation}

We suggest that the patient's view of the risk and benefit in deciding whether to undergo complex procedures, including renal transplantation, should always carry significant weight in the eventual decisions reached. (2D)

\section{Cardiovascular disease in CKD (CVD) (Guidelines CVD 5.1-5.7)}

\section{Guideline 5.1 - CVD: Hypertension in non-dialysis patients}

We suggest that BP in CKD 1-4 should be managed according to NICE guidance: $<140 / 90$ in patients without significant proteinuria and $<130 / 80$ in those with proteinuria or with diabetes. (2C)

\section{Guideline 5.2 - CVD: Hypertension in dialysis patients}

We suggest that pre- and post-dialysis blood pressure (measured after completion of dialysis, including washback) should be recorded and intra-dialytic blood pressure measurements should be made to facilitate good management of the HD session. (2D) 


\section{Guideline 5.3 - CVD: Hypertension in dialysis patients}

We suggest that home or ambulatory blood pressure recordings should be performed if pre- and post-HD or clinic blood pressures are regularly elevated (>160 mmHg systolic BP for $>50 \%$ of the recording period) or there is concern over possible hypotension. $(2 \mathrm{C})$

\section{Guideline 5.4 - CVD: Hypertension in dialysis patients}

Blood pressure targets for dialysis patients are difficult to recommend in the absence of RCTs showing survival benefit, and even more difficult to achieve in practice. However we suggest that it would be sensible to avoid sustained BP extremes and, in order to try to provide some guidance we suggest that systolic blood pressure during the inter-dialytic period on $\mathrm{HD}$, and for $\mathrm{PD}$ patients, should not regularly exceed $>160 \mathrm{mmHg}$. (2C)

\section{Guideline 5.5 - CVD: Hypotension/Hypertension in dialysis patients}

We suggest that systolic blood pressure should not routinely be treated with pharmacological agents with antihypertensive properties if SBP is regularly $<120 \mathrm{mmHg}$ pre dialysis. Discussion with cardiological colleagues may be prudent if ACEI, ARB or BB are being used for LV systolic or diastolic dysfunction in the context of low BP. (2D)

\section{Guideline 5.6 - CVD: Hypertension in dialysis patients}

We suggest that dialysis patients should be on a restricted salt ( $<6 \mathrm{~g} /$ day $)$ diet. $(2 \mathrm{C})$
Guideline 5.7 - CVD: Hypertension in dialysis patients

We suggest that hypertension on dialysis should be managed by ultrafiltration in the first instance. (2D)

\section{Summary of Audit Measures for Cardiovascular Disease in CKD}

1. Compliance with recording of cardiovascular comorbidity at the time of referral to a renal unit and when starting renal replacement therapy.

2. Proportion of patients smoking and proportion referred for active help regarding cessation.

3. Proportion of patients performing regular exercise on haemodialysis

4. Record of glycated haemoglobin concentrations in IFCC $(\mathrm{mmol} / \mathrm{mol})$ and HBA1C\%.

5. Record of prescribed statins allied to indications and comorbidities of patients

6. Cholesterol concentrations in patients prescribed HMG CoA reductase inhibitors

7. Delay between referral to cardiology for an assessment for renal transplantation and the final cardiological sign-off indicating fitness to proceed should be less than 3 months.

8. Pre, post and interdialytic blood pressure in HD patients

9. Blood pressure in peritoneal dialysis patients

10. Home and/or ambulatory blood pressure recordings 


\section{Full Clinical Practice Guidelines}

\section{Cardiovascular disease in CKD (CVD) (Guidelines CVD 1.1-1.8)}

\section{Guideline 1.1 - CVD: Cardiovascular risk factors}

We recommend that a history of and risk factors for cardiovascular disease in patients with CKD Stage 1-5 and dialysis patients should be recorded in a format that permits audit of the management of such patients. (1B)

These should include:

- Angina and myocardial infarction

- Previous coronary angioplasty or coronary artery bypass grafting

- Stroke and transient ischaemic attack

- Previous carotid artery surgery or angioplasty

- Peripheral vascular disease or previous intervention

- Cardiac failure

- Arrhythmias (supraventricular and ventricular)

- Diabetes

- Ethnicity

\section{Guideline 1.2 - CVD: Cardiovascular risk factors}

We recommend that a healthy lifestyle should be encouraged in all CKD patients, including dialysis patients. (1C)

\section{Audit measure}

Record of cardiovascular co-morbidity at the time of referral to a renal unit and when starting renal replacement therapy

\section{Rationale for 1.1 and 1.2}

Patients with renal impairment have a higher burden of vascular disease than age matched controls at all levels of renal dysfunction [1] and cardiovascular disease is the main cause of death in these patients. This risk is more apparent in younger patients where for example a 35 year old man on dialysis has the same risk of a cardiovascular death as an 80 year old not on dialysis [2]. Accurate recording of traditional cardiovascular risk factors and co-morbid cardiovascular disease will enable adjustment for case-mix in analysis of patient outcomes.

Obesity is a risk factor in developing renal disease [3] and weight loss programmes can help obese pre-dialysis patients in reducing proteinuria, BP and rate of renal decline [4]. Exercise in addition to Orlistat and dietary intervention, and increasingly, bariatric surgery for very obese subjects, has also been used to help improve suitability for transplantation [5]. Fewer data are available for patients treated by PD.

In addition to traditional risk factors associated with increased risk of cardiovascular disease such as hypertension and hypercholesterolaemia, other factors complicate and may accelerate vascular disease in patients with CKD, notably disordered mineral metabolism [2]. While plentiful epidemiological evidence continues to accumulate relating plasma phosphate concentrations in particular to adverse outcomes, there are no RCTs of phosphate reduction to show any CV benefit from that intervention. Ethnicity also affects cardiovascular risk [6]. Anaemia was thought to play a role in the early development of cardiovascular disease and may still be important [7]. However the publication of several RCTs including CREATE [8], CHOIR [9], and in particular the placebo-controlled TREAT [10] have challenged the 'cardiovascular' rationale behind anaemia correction. This remains controversial and partial correction may be important, with different targets that may apply to different subgroups [11]. However it is now recognised that complete anaemia correction may not be advisable in pre-dialysis or dialysis patients [12].

Both anaemia and disorders of bone and mineral metabolism develop early in the course of CKD and may be detected when eGFR is below $60 \mathrm{ml} / \mathrm{min}$ (CKD Stage 3) and both are nearly universal in patients with CKD Stage 5 and 5D dialysis patients. Readers are referred to the Renal Association guidelines on anaemia and mineral and bone disorders in CKD at www.renal. org and the KDIGO guideline on mineral and bone disorders [13].

\section{Guideline 1.3 - CVD: Cardiovascular risk factors}

We suggest that smoking habits should be recorded and smoking should be actively discouraged in all patients with a reasonable life expectancy and strongly discouraged in those patients on the transplant waiting list. (2B)

\section{Audit measure}

Proportion of patients smoking and proportion referred for active help regarding cessation.

\section{Rationale}

Cigarette smoking is associated with an increased cardiovascular risk in the general population [14]. In $\mathrm{CKD}$, smoking is associated with more rapid progression 
of renal disease [15], higher levels of established renal failure [16] and higher cardiovascular mortality following transplantation $[17,18]$.

\section{Guideline 1.4 - CVD: Cardiovascular risk factors}

We suggest that exercise should be encouraged and patients, including dialysis patients, should be enrolled on regular exercise programmes, exercising 3 to 5 times weekly either during dialysis or between dialysis sessions. (2C)

\section{Audit measure}

Proportion of patients performing regular exercise on haemodialysis

\section{Rationale}

Exercise is of proven benefit in reducing cardiovascular risk in the general population. Reduced exercise capacity and muscle strength is detectable in Stage 3 $\mathrm{CKD}$ and is poor in dialysis patients compared to age matched controls [19]. Exercise training improves maximal exercise capacity, muscle strength and endurance in predialysis patients in all age groups [20].

Morphological and metabolic benefits in skeletal muscle have been well-documented in HD patients following exercise training programs and there may be other benefits e.g. in reducing restless leg syndrome. However the benefit of exercise in dialysis patients is based on small numbers of studies with few patients. In these studies, exercise is claimed to improve quality of life, haematocrit, enhance exercise capacity and $\mathrm{VO}_{2}$ max, and increase endurance and muscle strength [21-23] and contribute to improved work capacity. Regular exercise may also contribute to reduced mortality. In a study of 2,507 new dialysis patients mortality risk was highest in those patients with severe limitations to moderate or vigorous physical activity and lowest in patients exercising up to 4 to 5 times weekly [24]. There was no association between increased survival and daily exercise so this warrants further study. Exercise training can result in a beneficial effect within a few weeks in HD patients. Exercise programs also have been shown to improve blood pressure control and reduce arterial stiffness though the beneficial effects taper off after 1 month after stopping training. In a randomised clinical trial over 12 weeks intradialytic cycling and pre-dialysis strength training resulted in beneficial effects on behavioural change, physical fitness and quality of life [25]. Improvement is sustained up to 4 years but dropout rates from the exercise program are more likely to occur when the exercise program is between dialysis sessions rather than during dialysis [26].

The amount of exercise that patients should take is not known but studies usually describe graded exercise individualised to patients with both low cardiovascular exercises $(<3$ times a week for $<20$ minutes) or cardiovascular exercise that exceeds this. Benefits have been described with both approaches [27].

However, exercise is generally considered an important part of staying well and this should be taken into consideration when designing an exercise programs for patients with CKD.

\section{Guideline 1.5 - CVD: Cardiovascular risk factors}

We suggest that the target glycated haemoglobin $\left(\mathrm{HbAl}_{\mathrm{c}}\right)$ in all $\mathrm{CKD}$, dialysis and transplant patients with diabetes should be between $6.5 \%$ ( $48 \mathrm{mmol} /$ $\left.\mathrm{mmol} / \mathrm{HbA}_{0}\right)$ and $7.5 \%\left(58 \mathrm{mmol} / \mathrm{mmol} / \mathrm{HbA}_{0}\right) \cdot(2 \mathrm{C})$

\section{Audit measure}

Record of glycated haemoglobin concentrations in IFCC $(\mathrm{mmol} / \mathrm{mol})$ and $\mathrm{HBA} 1 \mathrm{C} \%$

\section{Rationale}

Previously $\mathrm{HbAlc}$ was measured using an assay method harmonised to the Diabetes Control and Complications Trial (DCCT) standard [28]. Recent international discussion of $\mathrm{HbAlc}$ methodology coordinated by the international federation of clinical chemistry (IFCC) has meant that all laboratories should move to new units of $\mathrm{HbAl}_{\mathrm{c}}$ expressed as a fraction of $\mathrm{HbA} 1_{c}$ with respect to $\mathrm{HgA}_{0}(\mathrm{mmol} / \mathrm{mol})$. Thus the agreed calculation to convert the DCCT\% value to the IFFC value is: IFCC $(\mathrm{mmol} / \mathrm{mol}$ $\left.\mathrm{HbA}_{0}\right)=(\mathrm{DCCT} \%-2.15) \times 10.929$ [29].

Measurement of $\mathrm{HbAl}_{\mathrm{c}}$ blood levels is an established tool to monitor glycaemic control in diabetic patients. Differences in methodology and a lack of standardisation between laboratories however have made comparisons between sites difficult. In type 1 diabetes the DCCT demonstrated that strict glycaemic control can both delay the onset and slow the progression of microvascular complications over a nine year period. The mean $\mathrm{HbAl}_{\mathrm{c}}$ values during the nine-year study were $7.2 \%(55 \mathrm{mmol} / \mathrm{mol})$ with intensive therapy and $9.1 \%$ $(76 \mathrm{mmol} / \mathrm{mol})$ with conventional therapy. Subsequent studies have confirmed these findings. In type 2 diabetes improved glycaemic control appears to provide a similar benefit in delaying microvascular complications. Strict glycaemic control slows the increase in urinary albumin excretion in CKD type 1 and type 2 patients [30]. The 
UKPDS also demonstrated that improved glycaemic control in newly diagnosed type 2 diabetic patients reduced the incidence of diabetic microvascular complications [31].

Though intensive glycaemic control can delay the onset and slow progression of retinopathy, nephropathy and neuropathy no intensive glycaemic control trial to date has resulted in a significant reduction in cardiovascular end points.

Observational studies suggest that $\mathrm{HbAl}_{\mathrm{C}}$ influences cardiovascular event rates [32] and survival [33]. However in a meta-analysis of 13 prospective cohort studies, 10 of which were in type 2 diabetics, the relative risk of any cardiovascular event was 1.18 (95\% CI 1.10-1.26) for every one-percentage point increase in glycated haemoglobin [34]. The Veterans Affairs Diabetes Trial (VADT) in type 2 diabetes showed that intensive treatment improves cardiovascular events but only in those with less extensively calcified coronary disease [35]. This may mean that for many dialysis patients there is less protective effect of intensive glucose control. Thus the effect of reaching an $\mathrm{HbAl}_{\mathrm{c}}$ of less than $7.5 \%$ in many elderly type 2 diabetics on dialysis may have a modest effect on outcome and needs to be weighed against the risk of hypoglycaemic events. Three recent studies in the non-CKD setting (VADT [35], ACCORD [36] and ADVANCE [37]) remind us that more intensive blood glucose control in the frailer older type 2 diabetic patient might be detrimental not beneficial [38]. HD per se has no significant long-term effect on glycaemic control in insulin-treated type 2 diabetic patients. In PD patients the glucose load may require an increase in insulin or oral hypoglycaemic drugs.

New-onset diabetes after renal transplantation (NODAT) occurs in between $2 \%$ and $54 \%$ of patients, depending on a large number of factors from age, gender and race to immunosuppressive protocols employed. It is associated with worse graft and patient survival. In the absence of contrary evidence it would seem sensible to aim for a similar $\mathrm{HbA} 1_{\mathrm{C}}$ target in transplanted patients with diabetes, but again no data exists specifically in this cohort.

Recommendations from other guidelines:

- JBS 2 recommend a $\mathrm{HbA} 1_{\mathrm{c}} \%$ target of $<6.5 \%$, with an audit standard of $<7.5 \%$ [39]

- NICE recommend for each individual the target $\mathrm{HbA} 1_{\mathrm{C}}$ should be set between $6.5 \%$ and $7.5 \%$ [40]

- KDOQI recommend a target of $<7.0 \%$ for people with diabetes irrespective of the presence or absence of CKD [41]

\section{Guideline 1.6 - CVD: Cardiovascular risk factors}

We recommend that statins (or 3 hydroxy-3methylglutaryl-coenzyme A reductase inhibitors) should be considered for primary prevention in all CKD Stages 1-4 and transplant patients with a 10-year risk of cardiovascular disease, calculated as $>20 \%$ according to the Joint British Societies' Guidelines. (1B)

\section{Guideline 1.7 - CVD: Cardiovascular risk factors}

We recommend that a total cholesterol of $<4 \mathrm{mmol} / \mathrm{l}$ or a $25 \%$ reduction from baseline, or a fasting low density lipoprotein (LDL)-cholesterol of $<2 \mathrm{mmol} / \mathrm{l}$ or a $30 \%$ reduction from baseline, should be achieved, whichever is the greatest reduction in all patients. (1B)

\section{Guideline 1.8 - CVD: Cardiovascular risk factors}

We suggest that statins should not be withdrawn from patients in whom they were previously indicated and should continue to be prescribed when such patients start renal replacement therapy (RRT) or change modality. (2C)

\section{Audit measures}

Record of prescribed statins allied to indications and comorbidities of patients

Cholesterol concentrations in patients prescribed HMG CoA reductase inhibitors

\section{Rationale for guidelines 1.6-1.8}

Management should seek to lower cardiovascular risk through a multidisciplinary approach to risk factors, targeting patients with and those who are at high risk of atherosclerotic events. This is the principle behind the Joint British Societies' Guidelines (JBS-2 2005), in defining cardiovascular risk [42]. Estimation of cardiovascular risk will require accurate recording of data for each patient regarding smoking, family history of premature vascular disease, blood pressure, total and HDL-cholesterol the presence of diabetes, in addition to age and gender.

Dyslipidaemia is very prevalent in CKD and is influenced by renal function and by degree of proteinuria. There is a reduction of total, HDL and LDL cholesterol concentrations as GFR declines; it is clearly known that significant hypoalbuminaemia secondary to heavy proteinuria, as seen in nephrotic syndrome, is accompanied by a secondary dyslipidaemia $[43,44]$. The use of statins in patients with CKD Stages 1-4 has been extensively studied and found to be safe and effective at reducing cardiovascular mortality [45]. There are also some data 
suggesting that their use may retard progression of renal disease via a non lipid mechanism [46]. This remains controversial and may only be answered (in 2011) by UK-HARP-2. A Cochrane review, incorporating the ALERT study [47], of the use of statins in the post transplantation setting concludes that these agents provide protection against cardiovascular events but there is as yet no evidence of a mortality benefit [45].

Studies in HD patients have shown a U-shaped relationship between serum cholesterol and subsequent mortality [48]. This counterintuitive association is probably an example of reverse causation: chronic disease, chronic inflammation, and malnutrition all cause a reduction in cholesterol levels and are strong independent risk factors for death.

Two large observational studies have suggested benefit from statins in the dialysis population $[49,50]$. However, much more powerful information has come with more recent large randomised controlled trials and the data from these do not support this position [51, 52]. Other trials, most notably UK-HARP-2, are ongoing to determine whether cholesterol lowering has a role in primary prevention of cardiovascular disease in dialysis patients [53].

Although hypercholesterolaemia may have the same role in atherogenesis this may have a smaller impact in dialysis patients as these patients may die from cardiovascular causes other than those directly related to coronary artery atheromatous disease. Sudden cardiac death is a good example. A recent Cochrane report on statins in dialysis patients, looked at studies of statin vs. placebo and failed to identify all cause mortality (10 studies) or cardiovascular mortality (9 studies) benefits from statin therapy [45]. However these studies do not suggest that there is any harm from such statin-based therapy, with side effect profiles being similar to those seen in the general population. Until further evidence is available the advice is to continue to treat these patients with statins to achieve the above targets.

\section{References}

1 van der Zee S, Baber U, Elmariah S, Winston J, Fuster V. Cardiovascular risk factors in patients with chronic kidney disease. Nat Rev Cardiol 2009;6(9):580-589

$\checkmark 2$ KDIGO clinical practice guideline for the diagnosis, evaluation, prevention, and treatment of Chronic Kidney Disease-Mineral and Bone Disorder (CKD-MBD). Kidney Int Suppl 2009;(113):S1-130

$\checkmark 3$ Munkhaugen J, Lydersen S, Widerøe T, Hallan S. Prehypertension, obesity, and risk of kidney disease: 20-year follow-up of the HUNT I study in Norway. Am J Kidney Dis 2009;54(4):638-646

4 Navaneethan SD, Yehnert H, Moustarah F, Schreiber MJ, Schauer PR, Beddhu S. Weight loss interventions in chronic kidney disease: a systematic review and meta-analysis. Clin J Am Soc Nephrol 2009;4(10): 1565-1574

5 Maclaughlin HL, Cook SA, Kariyawasam D, Roseke M, van Niekerk M, Macdougall IC. Nonrandomised Trial of Weight Loss With Orlistat, Nutrition Education, Diet, and Exercise in Obese Patients With CKD: 2-Year Follow-up. Am J Kidney Dis [Internet] 2009 Nov 16 [cited 2009 Dec 16]; Available from: http://www.ncbi.nlm.nih.gov/pubmed/ 19926371

6 Hippisley-Cox J, Coupland C, Vinogradova Y, Robson J, Minhas R, Sheikh A, et al. Predicting cardiovascular risk in England and Wales: prospective derivation and validation of QRISK2. BMJ 2008; 336(7659):1475-1482

7 Eckardt K, Scherhag A, Macdougall IC, Tsakiris D, Clyne N, Locatelli F, et al. Left ventricular geometry predicts cardiovascular outcomes associated with anemia correction in CKD. J Am Soc Nephrol 2009;20(12):2651-2660

8 Drüeke TB, Locatelli F, Clyne N, Eckardt K, Macdougall IC, Tsakiris D, et al. Normalisation of hemoglobin level in patients with chronic kidney disease and anemia. N Engl J Med 2006 Nov 16;355(20):2071-2084

9 Singh AK, Szczech L, Tang KL, Barnhart H, Sapp S, Wolfson M, et al. Correction of anemia with epoetin alfa in chronic kidney disease. N Engl J Med 2006;355(20):2085-2098
10 Pfeffer MA, Burdmann EA, Chen C, Cooper ME, de Zeeuw D, Eckardt $\mathrm{K}$, et al. A trial of darbepoetin alfa in type 2 diabetes and chronic kidney disease. N Engl J Med 2009;361(21):2019-2032

11 Szczech LA, Barnhart HX, Sapp S, Felker GM, Hernandez A, Reddan D, et al. A secondary analysis of the CHOIR trial shows that comorbid conditions differentially affect outcomes during anemia treatment. Kidney Int [Internet] 2009 Nov 4 [cited 2009 Dec 17]; Available from: http://www.ncbi.nlm.nih.gov/pubmed/19890274

12 Locatelli F, Covic A, Eckardt K, Wiecek A, Vanholder R. Anaemia management in patients with chronic kidney disease: a position statement by the Anaemia Working Group of European Renal Best Practice (ERBP). Nephrol Dial Transplant 2009;24(2):348-354

13 www.kdigo.org

14 Danaei G, Ding EL, Mozaffarian D, Taylor B, Rehm J, Murray CJL, et al. The Preventable Causes of Death in the United States: Comparative Risk Assessment of Dietary, Lifestyle, and Metabolic Risk Factors. PLoS Med 2009;6(4):e1000058

15 Halimi JM, Giraudeau B, Vol S, Cacès E, Nivet H, Lebranchu Y, et al. Effects of current smoking and smoking discontinuation on renal function and proteinuria in the general population. Kidney Int 2000;58(3):1285-1292

16 Bash LD, Astor BC, Coresh J. Risk of Incident ESRD: A Comprehensive Look at Cardiovascular Risk Factors and 17 Years of Follow-up in the Atherosclerosis Risk in Communities (ARIC) Study. Am J Kidney Dis [Internet] 2009 Nov 20 [cited 2009 Dec 16]; Available from: http:// www.ncbi.nlm.nih.gov/pubmed/19932544

17 Yavuz A, Tuncer M, Gürkan A, Demirba A, Süleymanlar G, Ersoy F, et al. Cigarette smoking in renal transplant recipients. Transplant Proc 2004;36(1):108-110

18 Kasiske BL, Klinger D. Cigarette smoking in renal transplant recipients. J Am Soc Nephrol 2000;11(4):753-759

19 Padilla J, Krasnoff J, Da Silva M, Hsu C, Frassetto L, Johansen KL, et al. Physical functioning in patients with chronic kidney disease. J Nephrol 2008;21(4):550-559 
20 Clyne N. The importance of exercise training in predialysis patients with chronic kidney disease. Clin Nephrol 2004;61(Suppl 1):S10-13

-21 Oh-Park M, Fast A, Gopal S, Lynn R, Frei G, Drenth R, et al. Exercise for the dialysed: aerobic and strength training during hemodialysis. Am J Phys Med Rehabil 2002;81(11):814-821

22 Painter P, Carlson L, Carey S, Paul SM, Myll J. Physical functioning and health-related quality-of-life changes with exercise training in hemodialysis patients. Am J Kidney Dis 2000;35(3):482-492

23 Painter P, Moore G, Carlson L, Paul S, Myll J, Phillips W, et al. Effects of exercise training plus normalisation of hematocrit on exercise capacity and health-related quality of life. Am J Kidney Dis 2002;39(2): 257-265

24 Stack AG, Molony DA, Rives T, Tyson J, Murthy BVR. Association of physical activity with mortality in the US dialysis population. Am J Kidney Dis 2005;45(4):690-701

-25 van Vilsteren MCBA, de Greef MHG, Huisman RM. The effects of a low-to-moderate intensity pre-conditioning exercise programme linked with exercise counselling for sedentary haemodialysis patients in The Netherlands: results of a randomised clinical trial. Nephrol Dial Transplant 2005;20(1):141-146

26 Kouidi E, Grekas D, Deligiannis A, Tourkantonis A. Outcomes of longterm exercise training in dialysis patients: comparison of two training programs. Clin Nephrol 2004;61(Suppl 1):S31-38

27 Takhreem M. The effectiveness of intradialytic exercise prescription on quality of life in patients with chronic kidney disease. Medscape J Med 2008;10(10):226

28 DCCT group. The effect of intensive treatment of diabetes on the development and progression of long-term complications in insulindependent diabetes mellitus. The Diabetes Control and Complications Trial Research Group. N Engl J Med 1993;329(14):977-986

-29 D'Orazio P, Burnett RW, Fogh-Andersen N, Jacobs E, Kuwa K, Külpmann WR, et al. Approved IFCC recommendation on reporting results for blood glucose: International Federation of Clinical Chemistry and Laboratory Medicine Scientific Division, Working Group on Selective Electrodes and Point-of-Care Testing (IFCC-SD-WG-SEPOCT). Clin Chem Lab Med 2006;44(12):1486-1490

- 30 Gilbert RE, Tsalamandris C, Bach LA, Panagiotopoulos S, O’Brien RC, Allen TJ, et al. Long-term glycemic control and the rate of progression of early diabetic kidney disease. Kidney Int 1993;44(4):855-859

- 31 UKPDS group. Intensive blood-glucose control with sulphonylureas or insulin compared with conventional treatment and risk of complications in patients with type 2 diabetes (UKPDS 33). UK Prospective Diabetes Study (UKPDS) Group. Lancet 1998;352(9131):837-853

- 32 Tsujimoto Y, Ishimura E, Tahara H, Kakiya R, Koyama H, Emoto M, et al. Poor glycemic control is a significant predictor of cardiovascular events in chronic hemodialysis patients with diabetes. Ther Apher Dial 2009;13(4):358-365

33 Oomichi T, Emoto M, Tabata T, Morioka T, Tsujimoto Y, Tahara H, et al. Impact of glycemic control on survival of diabetic patients on chronic regular hemodialysis: a 7-year observational study. Diabetes Care 2006;29(7):1496-1500

- 34 Selvin E, Marinopoulos S, Berkenblit G, Rami T, Brancati FL, Powe NR, et al. Meta-analysis: glycosylated hemoglobin and cardiovascular disease in diabetes mellitus. Ann Intern Med 2004;141(6):421-431

35 Reaven PD, Moritz TE, Schwenke DC, Anderson RJ, Criqui M, Detrano $\mathrm{R}$, et al. Intensive glucose-lowering therapy reduces cardiovascular disease events in veterans affairs diabetes trial participants with lower calcified coronary atherosclerosis. Diabetes 2009;58(11):2642-2648

- 36 Gerstein HC, Miller ME, Byington RP, Goff DC, Bigger JT, Buse JB, et al. Effects of intensive glucose lowering in type 2 diabetes. N Engl J Med 2008;358(24):2545-2559

37 Patel A, MacMahon S, Chalmers J, Neal B, Billot L, Woodward M, et al. Intensive blood glucose control and vascular outcomes in patients with type 2 diabetes. N Engl J Med 2008;358(24):2560-2572

38 Weiss IA, Valiquette G, Schwarcz MD. Impact of glycemic treatment choices on cardiovascular complications in type 2 diabetes. Cardiol Rev 2009;17(4):165-175

39 British Hypertension Society British Cardiac Society. JBS 2: Joint British Societies' guidelines on prevention of cardiovascular disease in clinical practice. Heart 2005;91(Suppl 5):v1-52

40 NICE Inherited Clinical Guideline G. Management of Type 2 Diabetes 2002

41 K/DOQI. KDOQI Clinical Practice Guidelines and Clinical Practice Recommendations for Diabetes and Chronic Kidney Disease. Am J Kidney Dis 2007;49(2 Suppl 2):S12-154

42 British Hypertension Society British Cardiac Society. JBS 2: Joint British Societies' guidelines on prevention of cardiovascular disease in clinical practice. Heart 2005;91(Suppl 5):v1-52

43 Shurraw S, Tonelli M. Statins for treatment of dyslipidemia in chronic kidney disease. Perit Dial Int 2006;26(5):523-539

44 Hull RP, Goldsmith DJA. Nephrotic syndrome in adults. BMJ 2008; 336(7654):1185-1189

45 Navaneethan SD, Nigwekar SU, Perkovic V, Johnson DW, Craig JC, Strippoli GFM. HMG CoA reductase inhibitors (statins) for dialysis patients. Cochrane Database Syst Rev. 2009;(3):CD004289

46 Sukhija R, Bursac Z, Kakar P, Fink L, Fort C, Satwani S, et al. Effect of statins on the development of renal dysfunction. Am J Cardiol 2008; 101(7):975-979

47 Holdaas H, Fellström B, Jardine AG, Holme I, Nyberg G, Fauchald P, et al. Effect of fluvastatin on cardiac outcomes in renal transplant recipients: a multicentre, randomised, placebo-controlled trial. Lancet 2003;361(9374):2024-2031

48 Goldwasser P, Mittman N, Antignani A, Burrell D, Michel MA, Collier J, et al. Predictors of mortality in hemodialysis patients. J Am Soc Nephrol 1993;3(9):1613-1622

-49 Mason NA, Bailie GR, Satayathum S, Bragg-Gresham JL, Akiba T, Akizawa T, et al. HMG-coenzyme a reductase inhibitor use is associated with mortality reduction in hemodialysis patients. Am J Kidney Dis. 2005;45(1):119-126

-50 Seliger SL, Weiss NS, Gillen DL, Kestenbaum B, Ball A, Sherrard DJ, et al. HMG-CoA reductase inhibitors are associated with reduced mortality in ESRD patients. Kidney Int 2002;61(1):297-304

- 51 Wanner C, Krane V, Marz W, Olschewski M, Mann JF, Ruf G, et al. Atorvastatin in Patients with Type 2 Diabetes Mellitus Undergoing Hemodialysis. N Engl J Med 2005;353(3):238-248

52 Fellstrom BC, Jardine AG, Schmieder RE, Holdaas H, Bannister K, Beutler J, et al. Rosuvastatin and Cardiovascular Events in Patients Undergoing Hemodialysis. N Engl J Med 2009;360(14):1395-1407

53 Baigent C, Landray M, Leaper C, Altmann P, Armitage J, Baxter A, et al. First United Kingdom Heart and Renal Protection (UK-HARP-I) study: biochemical efficacy and safety of simvastatin and safety of low-dose aspirin in chronic kidney disease. Am J Kidney Dis 2005;45(3):473-484. 


\section{Cardiovascular disease in CKD (CVD) (Guidelines CVD 2.1-2.3)}

\section{Guideline 2.1 - CVD: B vitamin and folate supplementation}

We suggest that folic acid and B vitamin supplements should be offered to all renal patients considered nutritionally at risk from deficiency of folic acid or B vitamin deficiency. B12 levels and, serum and red cell folate should be above the lower limit of the reference range in all CKD patients including patients on dialysis and after transplantation. (2C)

\section{Guideline 2.2 - CVD: Folate deficiency}

We suggest that red cell folate levels should be checked if $\mathrm{MCV}$ remains high despite normal or high serum folate. $(2 \mathrm{C})$

Guideline 2.3 - CVD: Hyperhomocysteinaemia and vitamin supplementation

We suggest that serum folate levels and B12 should be checked 6 monthly in CKD4/5 and 3 monthly in dialysis patients or more frequently if patients remain anaemic or deficient on initial sampling. There is insufficient evidence of the effects of these vitamins on modifying vascular risk by effects on homocysteine in dialysis patients to recommend supraphysiological replacement. (2D)

\section{Rationale for Guidelines 2.1-2.3}

Homocysteine levels are associated with vascular disease in the general population and can be reduced by supplementation with folic acid by $\sim 25 \%$, and vitamin $\mathrm{B} 12$ by $\sim 7 \%$ [1], while vitamin $\mathrm{B} 6$ may have a minor role. There are of course sound haematopoetic rationales for the use of these supplements if there is anaemia or macrocytosis which can be attributed to deficiency of folate [2]. Folate deficieny occurs within 3-6 months if no intake is given.

Homocysteine levels are higher in patients with all levels of renal impairment [3], and are $\sim 3$ times higher in patients with established renal failure [4]. The elevation of homocysteine levels seen in CKD mirrors closely the degree of loss of renal function; indeed this is a major potential confounder when considering epidemiological associations between plasma homocysteine concentrations and adverse events. While there does seem to be in most series and meta-analyses a graded relationship between adverse outcomes and plasma homocysteine concentrations in CKD [5], some would argue that there is significant reverse causality in operation with inflammation and malnutrition being more prevalent with lower levels [6].

Intriguingly, acute administration of IV folate may have some vascular protective effects in HD patients [7] but this needs confirming, and, there is no evidence yet that these vascular changes will impact favourably on outcomes. This area is further complicated by the possibility that folate/folinic acid may have biological effects which are not related to any alteration in plasma homocysteine concentrations.

The homocysteine response to these vitamins varies in established renal failure, but there is no problem with absorption of these vitamins in HD patients [8]. However there may be differences in response to these vitamins on homocyteine levels between $\mathrm{HD}$ and $\mathrm{PD}$ patients [9]. Mutations in the gene regulating methylenetetrahydrofolate reductase, which increase homocystine levels in patients with renal failure, are associated with enhanced cardiovascular mortality [10]. RCTs of vitamin treatment in the general population with normal kidney function have been largely negative [11]. Trials of vitamins in renal failure have been equally disappointing [3]. Specifically, there was no overall benefit on mortality [12], or on cognitive function [13] as a result of folate supplementation. Folate deficieny is rare in countries that supplement foods routinely with this vitamin. Nevertheless correction of folate deficiency is good clinical practice irrespective of putative effects on homocysteine levels or vascular disease risk.

In stable renal transplant recipients an elevated fasting homocysteine blood level is an independent risk factor for cardiovascular disease [14]. The ongoing FAVORIT study may provide evidence as to whether standard multivitamin therapy including folic acid and vitamins B12 will affect cardiovascular outcomes in renal transplant recipients [15]. 


\section{References}

1 Homocysteine Lowering Trialists' Collaboration. Dose-dependent effects of folic acid on blood concentrations of homocysteine: a meta-analysis of the randomised trials. Am J Clin Nutr 2005;82(4):806-812

-2 Elliott J, Mishler D, Agarwal R. Hyporesponsiveness to erythropoietin: causes and management. Adv Chronic Kidney Dis 2009;16(2):94-100

$\checkmark 3$ Ganji V, Kafai MR. Demographic, health, lifestyle, and blood vitamin determinants of serum total homocysteine concentrations in the third National Health and Nutrition Examination Survey, 1988-1994. Am J Clin Nutr 2003;77(4):826-833

4 Heinz J, Domröse U, Luley C, Westphal S, Kropf S, Neumann KH, et al. Influence of a supplementation with vitamins on cardiovascular morbidity and mortality in patients with end-stage renal disease: design and baseline data of a randomised clinical trial. Clin Nephrol 2009;71(3):363-365

5 Zoccali C, Mallamaci F, Tripepi G. It is important to lower homocysteine in dialysis patients. Semin Dial 2007;20(6):530-533

6 Suliman M, Stenvinkel P, Qureshi AR, Kalantar-Zadeh K, Bárány P, Heimbürger $\mathrm{O}$, et al. The reverse epidemiology of plasma total homocysteine as a mortality risk factor is related to the impact of wasting and inflammation. Nephrol Dial Transplant 2007;22(1):209-217

7 Tochihara Y, Whiting MJ, Barbara JA, Mangoni AA. Effects of pre- vs. intra-dialysis folic acid on arterial wave reflections and endothelial function in patients with end-stage renal disease. Br J Clin Pharmacol 2008;66(5):717-722

8 Ghandour H, Bagley PJ, Shemin D, Hsu N, Jacques PF, Dworkin L, et al. Distribution of plasma folate forms in hemodialysis patients receiving high daily doses of L-folinic or folic acid. Kidney Int 2002;62(6):22462249

9 Urquhart BL, House AA. Assessing plasma total homocysteine in patients with end-stage renal disease. Perit Dial Int 2007;27(5):476-488

10 Jamison RL, Shih M, Humphries DE, Guarino PD, Kaufman JS, Goldfarb DS, et al. Effect of the MTHFR C677T and A1298C polymorphisms on survival in patients with advanced CKD and ESRD: a prospective study. Am J Kidney Dis 2009;53(5):779-789

11 Lonn E, Yusuf S, Arnold MJ, Sheridan P, Pogue J, Micks M, et al. Homocysteine lowering with folic acid and B vitamins in vascular disease. N Engl J Med 2006;354(15):1567-1577

12 Vianna ACA, Mocelin AJ, Matsuo T, Morais-Filho D, Largura A, Delfino VA, et al. Uremic hyperhomocysteinemia: a randomised trial of folate treatment for the prevention of cardiovascular events. Hemodial Int 2007;11(2):210-216

13 Brady CB, Gaziano JM, Cxypoliski RA, Guarino PD, Kaufman JS, Warren $\mathrm{SR}$, et al. Homocysteine lowering and cognition in CKD: the Veterans Affairs homocysteine study. Am J Kidney Dis 2009;54(3):440-449

14 Ducloux D, Motte G, Challier B, Gibey R, Chalopin JM. Serum total homocysteine and cardiovascular disease occurrence in chronic, stable renal transplant recipients: a prospective study. J Am Soc Nephrol 2000;11(1):134-137

15 Bostom AG, Carpenter MA, Hunsicker L, Jacques PF, Kusek JW, Levey AS, et al. Baseline characteristics of participants in the Folic Acid for Vascular Outcome Reduction in Transplantation (FAVORIT) Trial. Am J Kidney Dis 2009;53(1):121-128. 


\section{Cardiovascular disease in CKD (CVD) (Guidelines CVD 3.1-3.6)}

\section{Guideline 3.1 - CVD: Secondary prevention of cardiovascular risk}

We recommend that CKD Stage 1-3 patients with a history of chronic stable angina, acute coronary syndrome, myocardial infarction, stroke, peripheral vascular disease, or who undergo surgical or angiographic coronary revascularisation, should be prescribed aspirin, an ACE inhibitor, a beta-blocker, and an HMG-CoA reductase inhibitor unless contraindicated as per NICE Guidance. (1B)

\section{Guideline 3.2 - CVD: Secondary prevention of cardiovascular risk}

We suggest that CKD Stage 4/5 patients (including those on dialysis and after transplantation) with a history of chronic stable angina, acute coronary syndrome, myocardial infarction, stroke, peripheral vascular disease, or who undergo surgical or angiographic coronary revascularisation, should be prescribed aspirin, an ACE inhibitor, a beta-blocker, and an HMG-CoA reductase inhibitor unless contraindicated as per NICE Guidance. $(2 \mathrm{C})$

\section{Guideline 3.3 - CVD: Secondary prevention of cardiovascular risk}

We suggest that aspirin and clopidogrel may be indicated for up to 12 months post angioplasty and stenting and in non-ST elevation MI but may have an excess of bleeding complications. (2C)

\section{Guideline 3.4 - CVD: Secondary prevention of cardiovascular risk}

We suggest that aspirin is indicated for secondary prevention but not primary prevention of vascular disease in renal failure. $(2 \mathrm{C})$

\section{Guideline 3.5 - CVD: Secondary prevention of cardiovascular risk}

We suggest that the doses of ACE inhibitors and beta-blockers should be titrated upwards towards the maximal effective and tolerated doses. (2C)

\section{Guideline 3.6 - CVD: Secondary prevention of cardiovascular risk}

We suggest that patients on lipid-lowering drug treatment should have total cholesterol reduced by $25 \%$ or to below $4 \mathrm{mmol} / \mathrm{l}$, or LDL-cholesterol to below $2 \mathrm{mmol} / \mathrm{l}$, or reduced by $30 \%$, whichever reductions are the greatest. (2B)

\section{Audit measures}

Cholesterol concentrations in patients prescribed HMG CoA reductase inhibitors

\section{Rationale for 3.1-3.6}

Survival after myocardial infarction in CKD patients is poor and correlates with the degree of renal impairment [1]. There is evidence for underuse of guideline based therapies in this group but this does not account for all the excess risk conferred by renal impairment [2].

Guidelines for the management of non-renal patients with proven cardiovascular disease should be followed [3]. This includes both non-pharmacological therapies (Guidelines 1.2-1.4) and pharmacological treatments with ACE inhibitors, beta-adrenergic blockers, aspirin and $\mathrm{HMG}-\mathrm{CoA}$ reductase inhibitors.

Recent data have cast doubt on the role of aspirin for primary prevention of vascular disease in all but the very high risk individual with normal renal function because of the risk of haemorrhagic stroke and the relatively low (compared with secondary prevention patients) risk of a vascular event [4]. There are no data that allow us to know this information in patients with renal impairment, although the benefits appear to outweigh the risks in secondary prevention in both the normal and the CKD patient. There are conflicting data, and observational studies have raised some concerns, that aspirin may not be as safe in established renal failure. Analysis of DOPPS data [5] suggests that it reduces stroke but failed to demonstrate benefit in cardiovascular disease - indeed, there was an excess incidence of MI in aspirin users, but there are confounding factors that make these data difficult to interpret. The safety study that preceded UK-HARP-2, known as UK-HARP-1 [6] which included aspirin use, did not suggest any special safety concerns. There are no randomised controlled studies of the use of aspirin in CKD patients, and current advice is that aspirin for secondary prevention probably should be prescribed at 'low dose' (75-150) $\mathrm{mg}$ in patients with CKD 5 [7].

Clopidogrel similarly has a lack of RCT data but some studies, although not looking at this outcome, suggest that it is safe [8] and thus it could be used for secondary prevention in those intolerant of aspirin. The combination of aspirin and clopidogrel is suggested as secondary prevention up to 12 months after angioplasty and in non STEMI. This combination was beneficial overall in a 
retrospective analysis of Clopidogrel in Unstable angina to prevent Recurrent Events (CURE) data in patients with renal impairment with a moderate increase in the risk of haemorrhage [9].

\section{References}

- 1 Wright RS, Reeder GS, Herzog CA, Albright RC, Williams BA, Dvorak $\mathrm{DL}$, et al. Acute myocardial infarction and renal dysfunction: a highrisk combination. Ann Intern Med 2002;137(7):563-570

-2 Peterson PN, Ambardekar AV, Jones PG, Krumholz HM, Schelbert E, Spertus JA, et al. Increased mortality among survivors of myocardial infarction with kidney dysfunction: the contribution of gaps in the use of guideline-based therapies. BMC Cardiovasc Disord 2009;9:29

3 British Hypertension Society British Cardiac Society. JBS 2: Joint British Societies' guidelines on prevention of cardiovascular disease in clinical practice. Heart 2005;91(Suppl 5):v1-52

-4 Baigent C, Blackwell L, Collins R, Emberson J, Godwin J, Peto R, et al. Aspirin in the primary and secondary prevention of vascular disease: collaborative meta-analysis of individual participant data from randomised trials. Lancet 2009;373(9678):1849-1860

5 Ethier J, Bragg-Gresham JL, Piera L, Akizawa T, Asano Y, Mason N, et al. Aspirin prescription and outcomes in hemodialysis patients: the Dialysis
The rationale for the use of HMG-CoA reductase inhibitors in $\mathrm{CKD}$ is discussed in the rationale after Guidelines CVD 1.6-1.8.
Outcomes and Practice Patterns Study (DOPPS). Am J Kidney Dis 2007;50(4):602-611

6 Baigent C, Landray M, Leaper C, Altmann P, Armitage J, Baxter A, et al. First United Kingdom Heart and Renal Protection (UK-HARP-I) study: biochemical efficacy and safety of simvastatin and safety of low-dose aspirin in chronic kidney disease. Am J Kidney Dis 2005;45(3):473-484

-7 Notaro LA, Usman MH, Burke JF, Siddiqui A, Superdock KR, Ezekowitz MD. Secondary prevention in concurrent coronary artery, cerebrovascular, and chronic kidney disease: focus on pharmacological therapy. Cardiovasc Ther 2009;27(3):199-215

8 Dember LM, Beck GJ, Allon M, Delmez JA, Dixon BS, Greenberg A, et al. Effect of clopidogrel on early failure of arteriovenous fistulas for hemodialysis: a randomised controlled trial. JAMA 2008;299(18):2164-2171

9 Keltai M, Tonelli M, Mann JFE, Sitkei E, Lewis BS, Hawken S, et al. Renal function and outcomes in acute coronary syndrome: impact of clopidogrel. Eur J Cardiovasc Prev Rehabil 2007;14(2):312-318 


\section{Cardiovascular disease in CKD (CVD) (Guidelines CVD 4.1-4.3)}

\section{Guideline 4.1 - CVD: Cardiac investigations and coronary revascularisation}

We suggest that CKD and dialysis patients should have unimpeded access to a full range of cardiac investigations including exercise and stress echocardiography, radioisotopic cardiac scans, and coronary angiography. They should also have unimpeded access to cardiology assessment for coronary angioplasty, coronary stenting and cardiac surgery. (2D)

\section{Guideline 4.2 - CVD: Cardiac investigations and coronary revascularisation}

We suggest that there should be no clinically important delay for pre-dialysis and dialysis patients in receiving assessment by cardiology colleagues for their suitability for transplantation. These issues are often best addressed by regular/joint working with other disciplines. (2D)

\section{Guideline 4.3 - CVD: Cardiac investigations and coronary revascularisation}

We suggest that the patient's view of the risk and benefit in deciding whether to undergo complex procedures, including renal transplantation, should always carry significant weight in the eventual decisions reached. (2D)

\section{Audit measure}

Delay between referral to cardiology for an assessment for renal transplantation and the final cardiological sign-off indicating fitness to proceed should ideally be less than 3 months

\section{Rationale for 4.1-4.3}

Diagnosis of coronary disease in dialysis patients may be problematic. Angina with normal coronary arteries is not uncommon [1], but is matched by an equally high prevalence of clinically silent coronary disease [2]. Standard exercise electrocardiography is often difficult because of poor exercise tolerance and a high prevalence of pre-existing electrocardiographic abnormalities. Minimising premature deaths by revascularisation in patients with prognostically important coronary disease should not depend on whether a patient has CKD or is on dialysis. Many such patients will only be identified by coronary angiography so dialysis patients should benefit from this intervention [3]. It is particularly important to identify patients on the waiting list for transplantation who might have coronary disease, to minimise the risk of intra- or post-operative death from myocardial infarction either by removing such patients from the list or by revascularisation. However, sensible though this sounds, it has not been demonstrated to be beneficial clinically. Moreover, if there is significant delay in receiving all of the appropriate investigations, there is a risk of a patient succumbing to a dialysis-related adverse event before having a chance to be transplanted. This is especially important in the pre-dialysis, pre-emptive transplantation setting, and also for patients with identified living renal transplant donors.

Risk markers for the presence of coronary artery disease in dialysis patients include:

- symptomatic angina

- unexplained arrythmias

- recurrent dialysis-related hypotension

- heart failure, ECG abnormalities

- wall motion abnormalities on echocardiography

Decisions on whether a patient is 'fit' for renal transplantation, therefore, have to be made on an individual basis, taking into account the patient's views and knowledge of their likely survival on dialysis. These decisions will also be influenced by local policy governing access to the transplant waiting list (see Renal Transplantation module). Prophylactic coronary intervention is controversial and is not currently advocated [4].

Percutaneous angioplasty with or without stenting [5] and surgical revascularisation [6] are associated with worse survival, a higher complication rate and higher re-stenosis rates in CKD patients compared to subjects without significant CKD. However similar survival rates are found when comparing coronary revascularisation in dialysis patients with CKD patients Stages 3-5 not on dialysis. The ARTS trial was designed to compare coronary artery stenting with bypass surgery for multivessel coronary disease in patients with CKD Stages 3-5. 142 patients with multivessel coronary disease were randomly assigned to stent implantation $(n=69)$ or CABG $(n=73)$. At 5 years, there was no significant difference between the two groups in terms of cardiovascular or all cause mortality [5]. In those patients who survived without a cardiovascular event $18.8 \%$ in the stent group underwent a second revascularisation procedure compared to $8.2 \%$ in the surgery group $(P=0.08)$. The event-free survival at 5 years was $50.7 \%$ in the stent group and $68.5 \%$ in the surgery group $(P=0.04)$. 


\section{References}

$\checkmark 1$ Roig E, Betriu A, Castañer A, Magriña J, Sanz G, Navarro-Lopez F. Disabling angina pectoris with normal coronary arteries in patients undergoing long-term hemodialysis. Am J Med 1981;71(3):431-434

- Kremastinos D, Paraskevaidis I, Voudiklari S, Apostolou T, Kyriakides Z, Zirogiannis $\mathrm{P}$, et al. Painless myocardial ischemia in chronic hemodialysed patients: a real event? Nephron 1992;60(2):164-170

-3 Sedlis SP, Jurkovitz CT, Hartigan PM, Goldfarb DS, Lorin JD, Dada M, et al. Optimal medical therapy with or without percutaneous coronary intervention for patients with stable coronary artery disease and chronic kidney disease. Am J Cardiol 2009;104(12):1647-1653
Pilmore H. Cardiac assessment for renal transplantation. Am J Transplant 2006;6(4):659-665

5 Aoki J, Ong ATL, Hoye A, van Herwerden LA, Sousa JE, Jatene A, et al. Five year clinical effect of coronary stenting and coronary artery bypass grafting in renal insufficient patients with multivessel coronary artery disease: insights from ARTS trial. Eur Heart J 2005;26(15):1488-1493

6 Rubenstein MH, Harrell LC, Sheynberg BV, Schunkert H, Bazari H, Palacios IF. Are patients with renal failure good candidates for percutaneous coronary revascularisation in the new device era? Circulation 2000;102(24):2966-2972 


\section{Cardiovascular disease in CKD (CVD) (Guidelines CVD 5.1-5.6)}

\section{Guideline 5.1 - CVD: Hypertension in non-dialysis patients}

We suggest that BP in CKD 1-4 should be managed according to NICE guidance: $<140 / 90$ in patients without significant proteinuria and $<130 / 80$ in those with proteinuria or diabetics. (2C).

\section{Guideline 5.2 - CVD: Hypertension in dialysis patients}

We suggest that pre- and post-dialysis blood pressure (measured after completion of dialysis, including washback) should be recorded and intra-dialytic blood pressure measurements should be made to facilitate good management of the HD session. (2D)

\section{Guideline 5.3 - CVD: Hypertension in dialysis patients}

We suggest that home or ambulatory blood pressure recordings should be performed if pre- and post-HD or clinic blood pressures are consistently elevated or there is concern over possible hypotension. (2C)

\section{Guideline 5.4 - CVD: Hypertension in dialysis patients}

Blood pressure targets for dialysis patients are difficult to recommend in the absence of RCTs showing survival benefit, and even more difficult to achieve in practice. However we suggest that it would be sensible to avoid sustained BP extremes and, in order to try to provide some guidance we suggest that systolic blood pressure during the inter-dialytic period on $\mathrm{HD}$ and for $\mathrm{PD}$ patients should not regularly exceed $>160 \mathrm{mmHg}$. (2C)

\section{Guideline 5.5 - CVD: Hypotension/Hypertension in} dialysis patients

We suggest that systolic blood pressure should not routinely be treated with pharmacological agents with antihypertensive properties if SBP is regularly $<120 \mathrm{mmHg}$ pre dialysis. Discussion with cardiological colleagues may be prudent if ACEI, ARB or BB are being used for LV systolic or diastolic dysfunction in the context of low BP. (2D)

\section{Guideline 5.6 - CVD: Hypertension in dialysis patients}

We suggest that dialysis patients should be on a restricted salt $(<6 \mathrm{~g} /$ day $)$ diet. $(2 \mathrm{C})$

\section{Guideline 5.7 - CVD: Hypertension in dialysis patients}

We suggest that hypertension on dialysis should be managed by ultrafiltration in the first instance. (2D)

\section{Audit measures}

Pre, post and interdialytic blood pressure in HD patients

Proportion of patients achieving $>50 \%$ of their predialysis SBP readings falling in the range $120-160 \mathrm{mmHg}$

Blood pressure in peritoneal dialysis patients

Home and/or ambulatory blood pressure recordings

\section{Rationale for 5.1-5.7}

Blood pressure (BP) has been confirmed as a major risk factor for renal [1] and cardiovascular mortality [2]. BP reduction in the general population has proven cardiovascular benefit [3] and similar benefit has advocated for patients with CKD 1-4 and these patients should be treated with antihypertensive agents as per NICE Guidance [4] which recommends BP targets for CKD 1-4 patients as follows:

In people with CKD aim to keep the systolic blood pressure below $140 \mathrm{mmHg}$ (target range $120-139 \mathrm{mmHg}$ ) and the diastolic blood pressure below $90 \mathrm{mmHg}$.

In people with diabetes and CKD or when the ACR is $\geqslant 70 \mathrm{mg} / \mathrm{mmol}$, or PCR $\geqslant 100 \mathrm{mg} / \mathrm{mmol}$ (approximately equivalent to $P C R \geqslant 100 \mathrm{mg} / \mathrm{mmol}$, or urinary protein excretion $\geqslant 1.0 \mathrm{~g} / 24 \mathrm{~h}$ ) aim to keep the systolic blood pressure below $130 \mathrm{mmHg}$ (target range $120-129 \mathrm{mmHg}$ ) and the diastolic blood pressure below $80 \mathrm{mmHg}$.

The problem of interpreting BP values in CKD Stage $5 \mathrm{D}$ patients is very challenging indeed. In any individual there is a complex interplay between volume overload with salt (and water) which may be appropriately addressed by diuretics or dialysis, and/or vasoconstriction caused by neurohumoral mechanisms and this may treated with antihypertensive drugs. These mechanisms lead to vascular and cardiac dysfunction and may be important in the observation of the 'U-shaped' mortality curve seen when considering blood pressure in dialysis patients [5]. The most likely explanation of this counterintuitive relationship between blood pressure and mortality, is that in study cohorts, cardiac failure, whether due to hypertensive heart disease or to ischaemic heart disease, carries a high risk of early mortality and is associated with low blood pressure [6]. The NICE CKD1-4 guidance suggests that low blood pressures $(<120 / 60)$ are associated with adverse outcomes [4] but no full recommendations were made about this.

Nephron Clin Pract 2011;118(suppl 1):c125-c144 
Nevertheless, there were strong implications in these guidelines that lower pressures were suboptimal, perhaps by causing under perfusion of the coronary circuit. There are accumulating data in haemodialysis patients that suggest low blood pressure and other factors contribute to myocardial dysfunction during dialysis and this contributes to vascular morbidity and mortality [7]. Quite how best to respond to this particular challenge, awaits planned RCTs.

The correct measurement of $\mathrm{BP}$ in the setting of regular haemodialysis is especially challenging. Preparation and travel for dialysis, the practice of dialysis, and other factors such as the use of, or abandonment of, anti-hypertensive medication (and the effect of dialysis on the bioactivity of anti-hypertensives) all conspire to mean that the convenient (but often poorly standardised) practice of obtained BP levels just before and just after dialysis sessions is profoundly misleading. In the management of essential hypertension, care in the interpretation of blood pressure measurements is just as important - these should be taken while the patient is free from anxiety or stress. Current recommendations [8] suggest that blood pressure should be taken after five minutes rest in a chair, after at least 30 minutes of abstention from caffeine or nicotine, with the patient seated comfortably, and with the arm supported at heart level. At least two measurements should be taken, several minutes apart, to allow for the alerting response to blood pressure measurement. If the second measurement is significantly lower than the first, a third measurement should be taken, with further repeats if there is a further fall in measured blood pressure. The blood pressure recorded should be the mean of the later measurements. It is recognised that the practicalities of such recommendations mean that these are usually aspirational procedures and are sadly highly unlikely to be achieved in any UK renal unit outside of a clinical trial setting. Indeed many automated BP measurement taken in dialysis units were found to be $>14 / 7 \mathrm{mmHg}$ higher than standard human recordings [9]. Thus if pre and post HD blood pressures are consistently elevated, home or ambulatory blood pressure recordings should be considered in trying to confirm or refute the presence of inappropriately raised or lowered BP levels [10] in order to decide if treatment is required.

Ambulatory blood pressure measurement studies have demonstrated that pre and post dialysis blood pressure measurements are of little value in predicting the presence of left ventricular hypertrophy at echocardiography [11]. However, some data suggest that pre-dialysis SBP's
$>150-160$ are associated with excess mortality in haemodialysis patients $[12,13,14]$. Certainly very high SBP $(>200)$ pre dialysis seems to confer an adverse prognosis [15]. Home blood pressure recordings with a mean systolic BP $>150 \mathrm{mmHg}$ has a sensitivity of $80 \%$ and specificity of $84 \%$ for diagnosing hypertension, defined by ambulatory BP $>135 / 85$ between dialysis sessions [11]. Another recent study suggests that mortality is lowest when home systolic blood pressure was between 120-130 and ABPM SBP was 110-120 [16]. There are also data suggesting that haemodialysis patients lose their normal diurnal BP variation and this loss is independently associated with left ventricular mass [17]. On ABPM the blood pressure will also increase during the interdialytic period, so timing of the test will influence outcomes [18]. Moreover the size of the variability of pre dialysis BP measurements is associated with mortality [19]. There have been a few controlled trials suggesting that a blood pressure treatment, but not necessarily achieved BP, may be associated with improved outcome in HD patients [20,21].

However, there is a worry that lowering $\mathrm{BP}$ too aggressively may lead to intradialytic hypotension [22], which is an independent predictor of mortality [23, $24]$. Further data from some studies suggests excess mortality was associated with pre dialysis SBP $<120 \mathrm{mmHg}$ $[5,25]$. Patients with SBP $<111 \mathrm{mmHg}$ on $\mathrm{PD}$ are similarly at increased risk [26]. Thus patients who have persistently low pre-dialysis BP or recurrent intradialytic hypotension should be investigated further, with a view to changing target weight, reducing antihypertensive agents or investigating cardiac dysfunction. Preventing intradialytic hypotension may also retard the decline in residual renal function.

Pulse pressure is increasingly recognised as a more powerful predictor of mortality than diastolic or systolic pressure alone $[27,28]$ and fall in pulse pressure on dialysis may be beneficial [29]. Increased vascular and ventricular stiffness may mean that in dialysis patients, coronary perfusion (dependent on diastolic pressure) may need to be maintained by higher pressures.

There is therefore considerable debate about how and when to measure blood pressure and the targets for dialysis patients. These questions need investigation by properly organised randomised controlled trials and until then significant caution should be exercised in interpreting blood pressure guidelines. However, we feel that guideline writing committees have a duty to make some recommendations on this no matter how difficult [30], based on what evidence does exist. Thus 
while, there are not enough data to make robust recommendations, we have attempted to make some sensible suggestions, to avoid excessively high SBP (aim $<160 \mathrm{mmHg}$ ).

As a separate recommendation (albeit with even weaker evidence) we feel we that there is enough evidence accumulating evidence that that low blood pressures may be counterproductive, and that SBP should not be lowered with drugs to $<120 \mathrm{mmHg}$. These targets may therefore serve as a realistic target range which may be practically auditable and achievable in a large proportion of the dialysis population (based on UK Renal Registry data from the 12th Annual Report, published in 2009 and referring to 2008 data). Home or ambulatory blood pressure may be useful to confirm blood pressures in situations where patients are at risk of hypotension, e.g. elderly patients or those with symptoms of postural hypotension [31].
We make no recommendation about how this can be achieved, except that dietary salt restriction should be the default recommendation, and that ultrafiltration is used to achieve 'dry weight' (a phrase much used, but without a precise and robust definition). The KDIGO controversies conference report makes some suggestions with respect to treatment of hypertension in dialysis [32]. Longer term studies in patients without major comorbidities and studies on incident dialysis patient cohorts demonstrate improved survival when BP is corrected by whatever means [14, 33]. Two recent meta-analyses broadly support the concept of blood pressure lowering in patients on dialysis [27, 34]. Nevertheless, it is not at all clear whether the cardiovascular protection afforded by antihypertensive agents is due to blood pressure lowering or if these agents work through other protective mechanisms.

\section{References}

1 O’Seaghdha CM, Perkovic V, Lam TH, McGinn S, Barzi F, Gu DF, et al. Blood pressure is a major risk factor for renal death: an analysis of 560 352 participants from the Asia-Pacific region. Hypertension 2009;54(3): 509-515

- 2 Turnbull F, Neal B, Algert C, Chalmers J, Chapman N, Cutler J, et al. Effects of different blood pressure-lowering regimens on major cardiovascular events in individuals with and without diabetes mellitus: results of prospectively designed overviews of randomised trials. Arch Intern Med 2005;165(12):1410-1419

3 Law MR, Morris JK, Wald NJ. Use of blood pressure lowering drugs in the prevention of cardiovascular disease: meta-analysis of 147 randomised trials in the context of expectations from prospective epidemiological studies. BMJ 2009;338:b1665

4 National Collaborating Centre for Chronic Conditions. Chronic kidney disease: national clinical guideline for early identification and management in adults in primary and secondary care. 2008

5 Kalantar-Zadeh K, Kilpatrick RD, Kopple JD. Reverse epidemiology of blood pressure in dialysis patients. Kidney Int 2005;67(5):2067; author reply 2067-2068

6 Bos W, van Manen J, Noordzij M, Boeschoten E, Krediet R, Dekker F. Is the inverse relation between blood pressure and mortality normalised in 'low-risk' dialysis patients? J Hypertens [Internet] 2009 Nov 24 [cited 2009 Dec 15]; Available from: http://www.ncbi.nlm.nih.gov/pubmed/ 19940787

7 McIntyre CW, Burton JO, Selby NM, Leccisotti L, Korsheed S, Baker CSR, et al. Hemodialysis-induced cardiac dysfunction is associated with an acute reduction in global and segmental myocardial blood flow. Clin J Am Soc Nephrol 2008;3(1):19-26

-8 Ramsay L, Williams B, Johnston G, MacGregor G, Poston L, Potter J, et al. Guidelines for management of hypertension: report of the third working party of the British Hypertension Society. J Hum Hypertens 1999;13(9):569-592

-9 Rahman M, Griffin V, Kumar A, Manzoor F, Wright JT, Smith MC. A comparison of standardised versus 'usual' blood pressure measurements in hemodialysis patients. Am J Kidney Dis 2002;39(6):1226-1230

10 Alborzi P, Patel N, Agarwal R. Home blood pressures are of greater prognostic value than hemodialysis unit recordings. Clin J Am Soc Nephrol 2007;2(6):1228-1234

11 Agarwal R, Andersen MJ, Bishu K, Saha C. Home blood pressure monitoring improves the diagnosis of hypertension in hemodialysis patients. Kidney Int 2006;69(5):900-906

12 Zoccali C. Arterial pressure components and cardiovascular risk in end-stage renal disease. Nephrol Dial Transplant 2003;18(2):249-252

13 Mazzuchi N, Carbonell E, Fernández-Cean J. Importance of blood pressure control in hemodialysis patient survival. Kidney Int 2000; 58(5):2147-2154

14 Tomita J, Kimura G, Inoue T, Inenaga T, Sanai T, Kawano Y, et al. Role of systolic blood pressure in determining prognosis of hemodialysed patients. Am J Kidney Dis 1995;25(3):405-412

15 Li Z, Lacson E, Lowrie EG, Ofsthun NJ, Kuhlmann MK, Lazarus JM, et al. The epidemiology of systolic blood pressure and death risk in hemodialysis patients. Am J Kidney Dis 2006;48(4):606-615

16 Agarwal R. Blood Pressure and Mortality Among Hemodialysis Patients. Hypertension [Internet]. 2010 Jan 18 [cited 2010 Feb 13]; Available from: http://www.ncbi.nlm.nih.gov/pubmed/20083728

17 Rahman M, Griffin V, Heyka R, Hoit B. Diurnal variation of blood pressure; reproducibility and association with left ventricular hypertrophy in hemodialysis patients. Blood Press Monit 2005;10(1):25-32

18 Agarwal R, Light RP. Chronobiology of arterial hypertension in hemodialysis patients: implications for home blood pressure monitoring. Am J Kidney Dis 2009;54(4):693-701

19 Brunelli SM, Thadhani RI, Lynch KE, Ankers ED, Joffe MM, Boston R, et al. Association between long-term blood pressure variability and mortality among incident hemodialysis patients. Am J Kidney Dis 2008;52(4):716-726

20 Suzuki H, Kanno Y, Sugahara S, Ikeda N, Shoda J, Takenaka T, et al. Effect of angiotensin receptor blockers on cardiovascular events in patients undergoing hemodialysis: an open-label randomised controlled trial. Am J Kidney Dis 2008;52(3):501-506

21 Tepel M, Hopfenmueller W, Scholze A, Maier A, Zidek W. Effect of amlodipine on cardiovascular events in hypertensive haemodialysis patients. Nephrol Dial Transplant 2008;23(11):3605-3612 
22 Davenport A, Cox C, Thuraisingham R. Achieving blood pressure targets during dialysis improves control but increases intradialytic hypotension. Kidney Int 2008;73(6):759-764

23 Shoji T, Tsubakihara Y, Fujii M, Imai E. Hemodialysis-associated hypotension as an independent risk factor for two-year mortality in hemodialysis patients. Kidney Int 2004;66(3):1212-1220

24 Burton JO, Jefferies HJ, Selby NM, McIntyre CW. Hemodialysisinduced cardiac injury: determinants and associated outcomes. Clin J Am Soc Nephrol 2009;4(5):914-920

25 Zager PG, Nikolic J, Brown RH, Campbell MA, Hunt WC, Peterson D, et al. ' $U$ ' curve association of blood pressure and mortality in hemodialysis patients. Medical Directors of Dialysis Clinic, Inc. Kidney Int 1998;54(2):561-569

26 Goldfarb-Rumyantzev AS, Baird BC, Leypoldt JK, Cheung AK. The association between BP and mortality in patients on chronic peritoneal dialysis. Nephrol Dial Transplant 2005;20(8):1693-1701

-27 Agarwal R, Sinha AD. Cardiovascular protection with antihypertensive drugs in dialysis patients: systematic review and meta-analysis. Hypertension 2009;53(5):860-866

28 Agarwal R. Hypertension and survival in chronic hemodialysis patientspast lessons and future opportunities. Kidney Int 2005;67(1):1-13

29 Inrig JK. Intradialytic Hypertension: A Less-Recognised Cardiovascular Complication of Hemodialysis. Am J Kidney Dis [Internet]. 2009 Oct 21

\section{Acknowledgements}

Dr Stephen Holt wishes to declare the following potential conflicts of interest:

Honoraria from Amgen, Baxter and Sanofi-Aventis [cited 2009 Dec 15]; Available from: http://www.ncbi.nlm.nih.gov/ pubmed/19853337

30 Goldsmith D, Covic A. Blood pressure control in CKD Stage 5D patients - are we more or less certain what to do in 2009? Nephrol Dial Transplant 2009;24(12):3597-3601

- 31 Bangash F, Agarwal R. Masked hypertension and white-coat hypertension in chronic kidney disease: a meta-analysis. Clin J Am Soc Nephrol 2009;4(3):656-664

32 Levin NW, Kotanko P, Eckardt K, Kasiske BL, Chazot C, Cheung AK, et al. Blood pressure in chronic kidney disease stage 5D-report from a Kidney Disease: Improving Global Outcomes controversies conference. Kidney Int [Internet]. 2009 Dec 16 [cited 2009 Dec 19]; Available from: http://www.ncbi.nlm.nih.gov/pubmed/20016467

33 Lynn KL, McGregor DO, Moesbergen T, Buttimore AL, Inkster JA, Wells JE. Hypertension as a determinant of survival for patients treated with home dialysis. Kidney Int 2002;62(6):2281-2287

34 Heerspink HJL, Ninomiya T, Zoungas S, de Zeeuw D, Grobbee DE, Jardine MJ, et al. Effect of lowering blood pressure on cardiovascular events and mortality in patients on dialysis: a systematic review and meta-analysis of randomised controlled trials. Lancet 2009;373(9668): 1009-1015.
Dr David Goldsmith wishes to declare the following potential conflicts of interest: Honoraria or Consultancy Fees from Amgen, Baxter, Merck, Sanofi-Synthalabo, BMS, Roche, Shire, J + J, Takeda, Novartis and Sandoz. 